Finally, the symposium included discussion of substitutes for asbestos and recent work on man-made fibres (the subject of a recent conference in Copenhagen). Opinions ranged from the assertion that asbestos was highly dangerous and must be replaced by other materials as soon as possible to the equally confident claim that asbestos was a valuable and often irreplaceable material and substitutes had not been so thoroughly evaluated for their safety. Dr J C Wagner discussed the recent experimental work and mortality and morbidity studies on 32 man-made mineral fibre factories in Europe and the United States, which showed little if any evidence of health risks. In view of the evidence that fibre structure is more important than composition-long, fine fibres being the most dangerous ${ }^{5}$ - it should be possible to have safe man-made mineral fibres. But clearly there is a long way to go and the general view was that though these and other substitute materials should eventually replace asbestos they must first be proved safe. Not one of a panel of speakers, including an antiasbestos trade unionist, foresaw such replacement in the next 10 years.

Staff Editor,

DAPHNE GLOAG

British Medical fournal

1 Gloag D. Asbestos-can it be used safely? Br Med $71981 ; 282: 551-3$.

2 Gloag D. Asbestos fibres and the environment. Br Med $\mathcal{F} 1981$;282:623-6.

${ }^{3}$ Health and Safety Commission. Final report of the Advisory Committee on Asbestos. Vols 1 and 2. London: HMSO, 1979.

4 Zielhuis RL. Public health risks of exposure to asbestos. Report of a working group of experts prepared for the Commission of the European Communities, Directorate-General for Social Affairs, Health and Safety Directorate. Oxford: Pergamon Press, 1977.

${ }^{5}$ Stanton MF, Layard M, Tegeris A, et al. Relation of particle dimension to carcinogenicity in amphibole asbestoses and other fibrous minerals. f Natl Cancer Inst $1981 ; 67: 965-75$.

\section{A happier old age in Denmark?}

As we in Britain struggle to maintain an equilibrium between the rising numbers of very frail elderly people and the restrictions in public spending on services for them we can usefully look at the strategies of other European countries facing the same changes. Superficial comparisons may be misleading because of demographic differences or variations in nomenclature and the subdivisions of services. Particularly illuminating, therefore, is the March 1982 issue of the Danish Medical Bulletin, ${ }^{1}$ which comprises a series of commissioned articles (all in English) describing the whole range of services for the elderly in Denmark, their evolution, and the financial, administrative, and demographic background against which they operate. This volume is apparently available "free of charge to medical institutions on request" from the Danish Medical Association (Trondjhemsgade 9, DK-2100, Copenhagen $\varnothing$ ), though I hope that any medical readers in Britain will pass their copies on to their local directors of social services and district health administration chairmen.

How do the Danes differ from us ? Firstly, they have shown a much clearer political commitment to the dignity and rights of older people. Linking with this they view the care of the chronically handicapped as a social rather than a medical responsibility. Eschewing the use of their old hospitals as longstay repositories for geriatric patients, they have required their social service departments to widen the scope of their residential care to cater for the whole range of disabilities of our part III and geriatric long-stay clientele. Abandoning the conventional old people's homes, they used the affluence of the 1960 s and early 1970s to purpose-build large numbers of nursing homes offering this wider range of care under one roof. I have described elsewhere ${ }^{2}$ the excellence of these homes, of which I saw several on a visit sponsored by the King's Fund. Each resident is allowed to treat his own room as his home, surrounding himself with his own furniture and joining communal activities or not as he wishes. The staffing levels and facilities are such as to maintain him there (apart from acute spells of hospital care) for the rest of his life. Mandatory preadmission assessment by a geriatrician screens out those not yet needing such care, but, apart from the dying, no one would be rejected as too frail.

With six to seven places per 100 elderly the Danish nursing homes have well over twice the combined capacity of our part III and long-stay hospital sectors, though it is we rather than they who are out of line with other Northern European countries. Nevertheless, demand still exceeds supply, particularly in Copenhagen with its high (22\%) proportion of elderly; but, with sheltered housing and extensive and versatile day care and home help services also under its umbrella, the Danish Social Services Department can shift priorities in a way that would be quite impossible with the boundaries of our own system.

Despite its plentiful social services Denmark is relatively extravagant in hospital care. This is seen at its extreme in Copenhagen, ${ }^{3}$ whose half-million population is served by 5000 general hospital beds-of which over 2000 are medical, 200 geriatric, and 600 designated simply for people waiting for vacancies in nursing homes. With the acute specialties obliged to comply with any admission requested by a general practitioner and with domiciliary visiting rare, Danish geriatricians play little part in the community or in acute care, though their departments practise a high level of rehabilitation. I have little doubt that expansion of these departments and greater frontline activity could appreciably reduce the demand for bedsin the same way as that achieved by the better geriatric and psychogeriatric units in Britain.

These units are, indeed, the one aspect of the care of the elderly in which Britain may have a lead on Denmark, and if we are to avoid our district general hospitals grinding to a halt in the next 20 years we must invest in and not continue to dismantle these specialties. Our other main strength is in the burden of care of the elderly carried by families, though in many ways our actual services in the community compare unfavourably with Denmark's. We must give priority to increasing the support to such families through grannysitting schemes and more systematic day-care and relief admissions. For those without such support we must be prepared to take much more notice of the accumulating evidence of the extension of the range of warden-supervised care that can be achieved by adopting realistic staffing levels. ${ }^{4-6}$

Denmark's most direct lesson for us is in institutional care, setting standards of quality and homeliness that we just cannot ignore. The scope of the nursing home underlines the anachronism of our two-tier part III and hospital system, in which the part III units are having increasing difficulty in coping with the high levels of frailty and confusion of their new residents of today. The Department of Health and Social Security is flirting with the nursing-home concept but only within the framework of the National Health Service. Surely it must help social services departments through new guidelines on staffing, building, and joint funding to develop their newer homes along Danish lines. The Department of Health 
and Social Security will not, however, be able to afford this approach if it continues with its runaway subsidy through social security benefits of a boom in the private rest-home industry - over whose standards, admission criteria, and size it has virtually no control. If the facilities for the support of the physically frail in part III homes can be improved we ought then to consider the possibility of selecting residents on the basis of their suitability for a group/domestic setting rather than their level of physical dependency. This would leave the geriatric and psychogeriatric units to pool their long-stay resources to manage the aggressive, noisy, restless, and very confused patients who fit so badly into our homes, with a corresponding reduction in the amount of friction generated among the three services at present. Finally, Grundy and $\mathrm{Arie}^{7}$ have recently drawn attention to our low and relatively falling numbers of part III and long-stay hospital beds for the elderly. Clearly we cannot afford to allow this trend to continue, but we must be selective in any growth we can achieve, and sheltered housing and better back-up to family support seem to be our best buy.

Consultant Psychogeriatrician,

COLIN GODBER

Moorgreen Hospital,

Southampton SO3 3JB

1 Ammundsen E, co-ordinator. The elderly in Denmark: demographic, economic, social and health conditions. Dan Med Bull 1982;29:89-168.

2 Godber C. Danes' single door approach. Health and Social Services fournal 1979;89:100-3.

${ }^{3}$ Christensen G, Dalgaard OZ. The distribution of the hospital service in the city of Copenhagen. Dan Med Bull 1982;29:135-7.

4 Lewis RJ. Flying warden answers 80-year-old's Mayday call. Modern Geriatrics 1979;19:27-33.

5 Godber C. Kinloss Court: an experiment in sheltered housing and collaboration. Social Work Service 1978;15:42-5.

6 Brown DM. Kinloss Court Sheltered Housing Scheme. Research report No 29. Winchester: Hampshire County Council Social Services Department, 1981.

7 Grundy E, Arie T. Falling rate of provision of residential care for the elderly. Br Med $\mathcal{F} 1982 ; 284: 799-802$.

\section{Southampton's 10th anniversary}

If everything concerned with academic medicine seems gloomy at present, a sense of perspective can be restored by looking back at some of Britain's recent success stories in both undergraduate and postgraduate education. One such is the medical school at the University of Southampton, which has just held a conference to commemorate its 10th anniversary.

Southampton had been chosen as one of the new schools founded in the wake of the Todd Report for several reasons, said the foundation dean, Professor Donald Acheson. The university already had strong existing faculties in the preclinical sciences; a hospital building programme was under way and land was available for the school; there was a flourishing programme of postgraduate medical education throughout the region; and local enthusiasm, together with friendly collaboration between the university and the regional hospital board, would ensure that the medical school would have a truly regional role. That this last was not mere pious platitude but healthy reality was shown by the creation of an academic unit of renal medicine at Portsmouth, the formation of a medical library as part of a regional network, and the allocation of half the teaching to NHS staff. Other innovations were made in student selection: a wide range of A levels was permitted for entry, $15 \%$ of places were reserved for mature and graduate students, and students wère usually chosen without an interview. Since the first class of 40 students had been admitted in 1971 some 400 students had graduated and currently there were 600 in the school; nevertheless, Professor Acheson concluded, with a glance at present-day cuts a medical school aged only 10 years still needed care and attention.

Three main principles were followed in planning the curriculum at Southampton: education was to be life long, thereby blurring the distinction between so-called teaching and non-teaching hospitals; tuition was to take place more in the community than in the hospital; and the learning was to be integrated with teaching, so leading naturally to interdisciplinary teaching and to every student having an individual project to pursue.

The first year of the curriculum is concentrated on man, medicine, and society, with an emphasis on early medical contact-follow-up of a mother and child in the community after the mother has been seen initially in the antenatal clinic, for example. The student is also introduced to basic medical sciences. The second year ends with a clinical introductory course. In the third year are the traditional ward attachments to the main clinical specialties, arranged as four 10-week modules, together with attendance at a general practice for half a day a week (no less than $10 \%$ of a student's time is spent in general practice).

In these first three years, the present dean Professor Jack Howell pointed out, the student is introduced to an extraordinarily wide range of subjects and not unnaturally tends to generalise and oversimplify. On good Todd principles, the fourth year is designed to remedy such impressions by the student spending most of his time studying one topic in depth. This fourth year has aroused both interest and controversy, and predictably several formal presentations and seminars of intense discussion were devoted to it at this year's anniversary conference. The students' annual open sessions impress the visitor by the rigour of the individual approach, the knowledge of scientific method, and the well-rehearsed presentation of the results and crisp answers to questions. Surely, he thinks, this is the ideal way of learning about literature searches, controls, and the pitfalls of statistical analysis. On the other hand, many students worry that they have forgotten their clinical skills so that they will flounder in their final clinical year.

Certainly, said one regional teacher, Dr Peter Gillam, everybody should be told more about the aims of the fourthyear course and more should be done to overcome any possible drawbacks to a year spent mostly away from clinical medicine. Possibly a short reintroductory course at the beginning of the fifth year would be sufficient. Nevertheless, his survey had shown that other teachers considered Southampton graduates to be at least as good as those coming from other medical schools-and better in some respects. Another survey of 1971 entrants showed that $46 \%$ of the graduates replying were working in the Wessex region with careers similar to the national average but with a preference for general practice, medicine, and paediatrics and an unexplained reluctance to enter surgery and obstetrics and gynaecology.

Possibly, as some observers have claimed, in medical education process is unrelated to outcome: the actual curriculum is relatively unimportant compared with the characteristics of the person chosen and his or her subsequent experience after qualification. The curriculum at Southampton must be one of the most enjoyable available in Britain and its outcome is certainly no worse than the average. As with all things in medicine, more research is needed; but it is difficult to believe that when the class of ' 71 come to retire in 2016 they will not 